\title{
Na súa propia pel: contribucións autobiográficas á Guerra Civil. Conformación dunha narrativa singular
}

\section{On their Own Skin: An Autobiographic Contribution to the Civil War. Composition of a Peculiar Narration}

\author{
María Rodríguez SuÁRez \\ Universidade de Santiago de Compostela \\ IES Alfonso X O Sabio \\ maria.rodriguez.suarez@edu.xunta.es
}

[recibido 16/10/2014, aceptado 08/02/2015]

\section{RESUMO}

Neste artigo preténdese, a través dun conxunto de 16 narracións, ofrecer a visión autobiográfica dun grupo de autores que decidiron pór por escrito as súas vivencias de supervivencia na época da Guerra Civil.

PALABRAS CHAVE: Narrativa, autobiografías, Guerra Civil.

\section{RESUMEN}

En este artículo se pretende, a través de un conjunto de 16 narraciones, ofrecer la visión autobiográfica de un grupo de autores que decidieron poner por escrito sus vivencias de supervivencia en la época de la Guerra Civil.

PALABRAS Clave: Narrativa, autobiografías, Guerra Civil.

\section{ABSTRACT}

Through a collection of 16 stories, this article contains autobiographical anecdotes by a group of writers who survived the Spanish Civil War.

KEY WORDS: Narrative, autobiography, Civil War.

RodríGuez SuÁREz, Ma (2015): "Na súa propia pel: contribucións autobiográficas á Guerra Civil. Conformación dunha narrativa singular", Madrygal (Madr.), 18, Núm. Especial: 309-319.

SUMARIO: 1. Introdución. 2. Análise do corpus. 2.1. As obras. 2.2. O escritor e o personaxe: mesma ideoloxía, único obxectivo, a supervivencia. 2.3. Os espazos. 2.4. O tempo. 3. Conclusión. 4. Referencias bibliográficas. 


\section{INTRODUCIÓN}

Son moitas as narracións que se ocupan da época da Guerra Civil. Por esta razón, o estudo que segue restrínxese a aquelas obras que, en diferente grao, tocan esta temática dende os sufrimentos, venturas e desventuras dos seus autores. Recóllense aquí as pezas da literatura galega cuxos autores viviron e padeceron na súa persoa a guerra, e que ademais contribuíron a clarexar un pouco máis ese tempo histórico: as actuacións políticas clandestinas, os cárceres, as fuxidas e conseguinte exilio, os asasinatos, etc.

Estúdase a obra, e da man desta, a vida dun grupo de autores nados nos primeiros anos do século $\mathrm{XX}^{1}$, que ao plasmar por escrito as súas vivencias converteron os seus libros en verdadeiras xoias dunha época, en crónica histórica dun tempo que, setenta e cinco anos despois, aínda se está descubrindo. E permitiron que nós, lectores e lectoras,a coñecésemos.

Son, en definitiva, contribucións autobiográficas á Guerra Civil máis ou menos verídicas $^{2}$, pois pode que algúns dos datos achegados non sexan reais. Relatos, polo tanto, en maior ou menor medida realistas, focalizados dende a primeira persoa moitos deles.

Non interesan, xa que logo, as obras que transcorren nese trienio fatídico, pero cuxo autor non puido vivir, pola data de nacemento, ese momento. Así, quedan fóra novelas que relatan acontecementos certos como A maleta de Victoria Kent (por poñermos un exemplo actual) ou libros que están máis preto do estudo biográfico ou histórico, onde a vida dos seus protagonistas é contada tamén por un narrador omnisciente -diferente, polo tanto, do personaxe principal "novelado", e tamén maior ca este- que insire, en ocasións, entrevistas e outros documentados recompilados para un maior coñecemento desa época -pénsese n'Os irmáns Saco ou a loita galeguista baixo o franquismo, por citarmos só un exemplo. O criterio que aplicamos, pois, á hora de seleccionar Catro anos a bordo dunha illa e a excluír Os irmáns $\mathrm{Saco}^{3}$ é, basicamente, a coincidencia entre autor e personaxe principal -no caso das memorias ou autobiografías. Han ser obras escritas en primeira persoa -ou en terceira cando o personaxe principal sexa alter ego do autor e esteamos falando xa directamente de novelas-, polo que han ser obras de expresión subxectiva, centradas nun personaxe concreto e non en toda unha xeración, aínda que un personaxe poida simbolizar toda unha xeración ${ }^{4}$. Nestes casos, a ficción ocupará un segundo plano, pero non estará de todo ausente e, sobre todo, a compoñente introspectiva xogará un papel moi importante.

Polos motivos expostos, este estudo afástase dalgunhas das clasificacións que se desprenden dalgúns dos traballos consultados; concretamente da que inclúe a revista Biblos $\left(\mathrm{n}^{\circ} 21\right.$, 2006) ou da de Bertrand de Muñoz (1982) e, nalgún caso, da de Rodríguez Santamaría e Román Arén (2006) 5 .

Preténdese, en definitiva, reunir as novelas e as demais narracións -memorias, autobiografías...- que tocan o tema da Guerra Civil dende unhas perspectiva minimamente autobiográfica e cuxa temática xira en torno ao trienio bélico 1936-19395.

\footnotetext{
${ }^{1}$ Só Antón Alonso Ríos naceu a finais do século XIX (1887-1980).

${ }^{2}$ Somos conscientes de que ao facer estas consideracións entramos no perigoso terreo da verosimilitude, aquilo que non é necesariamente verdadeiro pero que ten aparencia de tal. Trátase, polo tanto, de contribucións polo menos cribles, polo congruente que resultan dentro do narrado.

${ }^{3}$ Pareceunos interesante contrapor dúas obras publicadasna mesma colección, o "Fardel da Memoria", da editorial A Nosa Terra.

${ }^{4}$ Por exemplo, a novela de Del Riego representa, segundo Xesús González: "as feblezas e a dignidade de toda unha xeración que foi fusilada, masacrada, asasinada, eivada" (González Gómez 1992: 19).

${ }^{5}$ Posiblemente o libro máis completo. Non obstante, é unha bibliografía sobre a novela. Non existe aínda unha obra definitiva que recolla de maneira rigorosa a narrativa da Guerra Civil (a maioría dos estudos céntranse, precisamente, na novela e non deixan de ser artigos ou pequenas contribucións).
} 
Quedarán tamén á marxe os contos ou relatos breves e serán todas as narracións aquí consideradas obras en galego de autores galegos $^{6}$. Outra cousa sería determinar cal foi a súa expresión orixinal, pois temos exemplos de obras escritas inicialmente en castelán ${ }^{7}$, pero logo traducidas. Nestes casos, manexaremos a versión galega. Quedan fóra, pois, as obras castelás de escritor galego, algunhas delas estudadas xa por Carballido Reboredo (2001) ou Bertrand de Muñoz (1982).

Entendemos que a produción castelá dos narradores galegos é moi interesante, como ben di Rodríguez Fer (2001 e 2006), pero subxacen impedimentos derivados da limitación deste artigo. Este traballo dedícase ao estudo "do material producido en lingua galega", aínda sabendo que

non hai autores monolingües en galego durante o período bélico e que existen moitos e moi importantes escritores galegos en castelán. A Guerra Civil española non é un fenómeno comprensible dende o sistema literario galego nin moito menos redutible a el... (Rodríguez Fer 2001: 7) ${ }^{8}$

E sendo conscientes de que é preciso tamén "ter a coherencia e a xenerosidade de considerar toda a literatura escrita por galegos (...) á marxe de calquera prexuízo fundamentado na exclusión ou na segregación" (Rodríguez Fer 2001: 7).

En canto á cronoloxía, un último apuntamento. É certo que as obras aquí seleccionadas non se cinxen exclusivamente ao período
1936-1939, pois algunhas tamén refiren a "agitación sociopolítica anterior y posterior a la contienda pues entran en el conjunto de causas, hechos y consecuencias de la guerra, conjunto que no se puede disgregar" (Bertrand de Muñoz 1982: 16). Estas pezas literarias tamén formarán parte do estudo, pois aínda que atinxan un período superior, o trienio está referido.

Téntase elaborar, polo tanto, unha clasificación o máis exhaustiva posible; aínda así é probable que queden fóra obras que si deberan aparecer. Non obstante, son tantas e algunhas tan descoñecidas ${ }^{9}$, que é difícil reunilas nun estudo destas características.

De feito, sobre a Guerra Civil tense escrito moito máis do que unha observación superficial podería supor. O que, non obstante, é unha percepción común, e non só aplicable á literatura galega nin moito menos ás obras autobiográficas:

la mayoría de la gente y, lo que es más grave, la mayoría de los críticos, ignora que se han publicado tantas obras novelescas inspiradas en la guerra española en numerosos países del mundo. Esto se debe a la carencia de fuentes bibliográficas serias y de trabajos panorámicos y a la información a menudo errónea. (Bertrand de Muñoz 1982: 11-12)

\section{ANÁLISE DO CORPUS}

Feitas estas precisións cabería establecer, agora, cales son as obras obxecto de estudo e a que xénero decidimos adscribilas. Non

'Carlos Fernández, por exemplo, naceu en Río de Xaneiro en 1909, pero criouse en Verín.

${ }^{7}$ A obra de Juan Noya publicouse en Caracas en 1976, na editorial Casuz, baixo o título Fuxidos. Memorias dun republicano gallego perseguido por el franquismo, con prólogo de Celso Emilio Ferreiro. Hoxe coñecemos a versión en galego con prólogo de Alonso Montero. Tamén Pola liberdade apareceu primeiro en México en 1956 co título Por la libertad. Cómo se lucha en España. Sabemos de Os que non morreron que foi escrita inicialmente en castelán, pero traducida polo propio autor ao galego para gañar en veracidade. E tamén que Catro anos a bordo dunha illa son "as memorias de Evaristo A. Mosquera, que saíran publicadas por primeira vez en castellano nos primeiros 80...” (Carballa 2006: 17).

${ }^{8}$ Volve insistir sobre o mesmo nas Xornadas de estudo e debate "Guerra Civil (1936-1939) e literatura galega" de 1999 (Alonso Montero e Miro Villar 2006: 174).

${ }^{9}$ Por exemplo, Memorias dun antifranquista,publicada nunha colección modesta -Embora-coa axuda da Asociación Cultural "Fuco Buxán” e do Concello de Fene.

${ }^{10}$ Basta, por exemplo, botar un ollo á Bibliografía de Un río de sangue e tinta para dar fe disto. 
obstante, pensamos que dirixir o noso esforzo e espazo ao segundo conformaría en si outro traballo, que as limitacións ás que estamos suxeitos non nolo permitirían. De maneira que optamos por ser laxos neste asunto e manter á marxe as cuestións de tipo epistemolóxico que $\mathrm{a}$ iso se encamiñarían ${ }^{11}$.

\subsection{AS OBRAS}

Estas son, pois, as narracións autobiográficas (ordenadas por data de publicación e co título reducido ${ }^{12}$ ) das que nos ocuparemos, divididas, por simplificar, en dous grupos: novelas (autobiográficas, realistas, sociais ou de aventuras) e non novelas (memorias, autobiografías, confesións ou diario, sen facer distingos). Ou o que é o mesmo: xénero ficcional e xénero non ficcional ou verídico.

\begin{tabular}{|l|l|} 
Novelas & Non novelas \\
\hline Non agardei por ninguén & Os que non morreron \\
\hline O silencio redimido & A crueldade inútil \\
\hline O siñor Afranio & Matádeo mañá \\
\hline Era tempo de apandar & Fuxidos \\
\hline Scórpio & Pola liberdade \\
\hline Terra coutada/Don Gabino & Memorias dun antifranquista \\
\hline O cego de Pumardedón & $\begin{array}{l}\text { Catro anos a bordo dunha } \\
\text { illa }\end{array}$ \\
\hline Esmoriz &
\end{tabular}

Pensamos que chegados a este punto, o máis acaído sería facermos un resumo argumental destas obras que nos sirva de introdución a cuestións máis específicas. No entanto, novamente, as limitacións de espazo fainos difícil este labor. De maneira que optamos por facer un estudo máis restrinxido que teña en conta, fundamentalmente, tres aspectos: causas que levaron o personaxe "novelado" (identificado co autor) a vivir a guerra como unha historia de supervivencia e causas que o levaron tamén a pór por escrito esa historia; espazos referidos e tempo.

\subsection{O ESCRITOR E O PERSONAXE: MES- MA IDEOLOXÍA, ÚNICO OBXECTIVO, A SUPERVIVENCIA}

Sabemos que a primeira característica común destes obras é a coincidencia entre autor e personaxe principal, mais tamén que esa equivalencia é en moitos casos "presentida", segundo a carga autobiográfica presente sexa maior ou menor. Así, nas obras "bautizadas" como "non novelas" esta equivalencia non pretende ser camuflada na ficción literaria a través da creación doutro personaxe que conte a historia. É máis importante o contido que a forma. De aí, que non semelle estraño que non sexan as grandes editoriais nas súas coleccións de novela as que se encarguen de publicalas.

Ao contrario, aparecerán en coleccións de ensaio (por exemplo, Matádeo mañá na colección Crónica de Xerais) ou outras destinadas, precisamente, a este tipo de literatura, como a mencionada "O fardel da memoria" de Edicións A Nosa Terra ou Ediciós do Castro. Son, sen dúbida, os relatos onde o autor xoga coa verosimilitude dos feitos narrados as que maiores problemas presentan (e non só de adscrición xenérica), por non seren só o soporte a través do cal contar unha etapa histórica; son obras ás que se lles presupón, ademais, certa calidade literaria (recompensada, por exemplo, en forma de galardóns: Premio Nacional de la Crítica a Scórpio en 1987 e Premio da Asociación de Críticos Españois de 1976 para $O$ silencio redimido).

Daquela, se algúns autores puideron atopar na publicación das súas obras unha compensación ao seu talento literario (ou a continuación ao seu labor de escritores), cal foi a razón da outra gran maioría? Sobre todo a dos autores que non deron revestimento novelesco ás súas obras e que non se achegaran antes á escrita literaria (ou que só o fixeran dun xeito moito máis puntual)? E doutra parte, por que é que

\footnotetext{
${ }^{11}$ Sobre este asunto insistiu a autora no seu traballo titorizado (Rodríguez Suárez 2006).

${ }^{12}$ Facémolo así para alixeirar a escrita e reducir espazo. É obvia a importancia do título ao completo (así como dos subtítulos e outra información paratextual).
} 
se viron envoltos como perseguidos e fuxidos nunha guerra ${ }^{13}$ da que logo dar conta literaria?

Unha análise respecto á segunda cuestión demostra que, entre os "escritores bélicos", algúns son personalidades de certa importancia, militantes de formacións políticas de esquerda -favorables ao pacto "frentepopulista"-, mentres que outros eran simples simpatizantes da República.

Os que máis abondan son os afiliados ao Partido Galeguista. Así, o personaxe co que identificamos a Ramón de Valenzuela na súa primeira novela, ou sexa, don Ozores, e con algunha reticencia o protagonista da segunda ${ }^{14}$; o señor Afranio de Alonso Ríos, o Mauro de Fernández del Riego, os personaxes de Carballo Calero (especialmente o personaxe de Salgueiro, posible alter ego do autor, que conta a historia de Scórpio ${ }^{15}$ ), Evaristo A. Mosquera, Elixio Rodríguez e Juan Noya.

Como afiliado ao Partido Comunista atopámonos a Enrique Vigo, mentres que de Izquierda Republicana seríao Xerardo Díaz ${ }^{16}$. Pola súa parte, Juan Noya foino da CNT (Confederación Nacional del Trabajo).
Sen ideoloxía definida hai que citar o Carlos Aranda de Silvio Santiago, Esmoriz de Aníbal Otero e os personaxes de Fernández Pérez; afíns, todos eles, aos postulados nacionalistas ou defensores nalgún momento desta causa. No caso de Silvio Santiago, colaborando na campaña a favor do estatuto na radio (aínda que nas páxinas da novela se defina como: monárquico, pero decepcionado coa proclamada República e non galeguista) e Fernández Pérez participando nos parladoiros con Otero e Risco ${ }^{17}$. O caso de Aníbal Otero é distinto: a el acúsano de comunista, que non rexeita, e declárase galeguista.

Vexamos agora algún fragmento sobre as presumibles razóns que os levaron a darlle forma escrita ás súas penurias de supervivencia; sen deixarmos de ter presente que moitas veces responden a un desabafo ${ }^{18}$ persoal. Así, sabemos que Evaristo A. Mosquera concibiu o libro a modo "reivindicativo":

- Como concebiu seu pai este libro?

- Meu pai non falaba moito do tema, pero nun momento da súa vida, xa xubilado, concebiu a idea de escribir un libro de memorias

\footnotetext{
${ }^{13}$ Non ter unha significación política non era, tampouco, impedimento para padecer as zunas franquistas.

${ }^{14}$ Non podemos deixar de ter presente que en 1962 Ramón de Valenzuela ingresa no Partido Comunista de España, aínda que as súas simpatías e colaboracións viñan de antes. E tampouco que foi conselleiro do Partido Galeguista por Lalín e A Estrada.

${ }^{15}$ Véxase Quiroga (1987).

${ }^{16}$ De todos os xeitos, véxase a entrevista que o de Porto de Son concedeu á xornalista María Esther Gilio (1989) e que recolle Dobarro (2007: 688):

- ¿Usted es del Partido Comunista?

-No, no.

— ¡Cómo se me ocurre! Usted tiene que ser anarquista.

-No, tampoco. Soy republicano.

-No dice mucho eso. En el Uruguay todos lo somos.

- Bueno, digamos que soy un frentista independiente.

${ }^{17}$ Realmente as causas da súa persecución parece que teñen que ver coa xenreira que lle tiña un veciño do lugar, Nelo Ventura, e non con que fose, un intelectual galeguista, autonomista e admirador de Castelao.

${ }^{18}$ Posiblemente o testemuño máis claro neste sentido o teñamos en Alonso Ríos, quen desexaba tapar un baleiro ("con el e coa sociedade en xeral") ao entregarlle o seu libro ("Eí che mando, moi breve, o resto das memorias. Moito me queda por decire de Moreiras e Portugal. Mais o esencial vai...”) a Xosé María Álvarez Blázquez; se ben gustase máis de contar oralmente a súa historia: "Pedinlle a Alonso Ríos que escribise as súas memorias daqueles anos dramáticos. Díxome que si, que xa ao tiña pensado (...) Falei logo cos amigos comúns para ver de convecelo de que non adiase máis a súa historia de fuxido. A resposta que un dos amigos me deu deixoume descorazonado: - O que máis lle gusta a Antón é contar esa historia. Se algún día a escribe xa non terá obxecto que a relate de palabra. Aí tes o problema" (Álvarez Blázquez 2006: 21).
} 
reivindicativo. Eran os primeiros anos oitenta e pensou que xa chegara o momento de contar esas vivencias que se concentran no que el pasou en San Simón nos catro anos que botou preso.

-Coñecía vostede esa biografía política ${ }^{19}$ ? (Carballa 2006: 17)

Ou que a Xerardo Díaz tamén o motivou, como acontece con Elixio Rodríguez, a ansia por "dar a coñecer ao mundo tan inxustificadas inmolacións" ${ }^{20}$. Pola súa banda, Juan Noya coméntanos:

Cos datos da parte sur do Baixo Miño, é dicir, dos que puiden averiguar e do que me corresponde en calidade de protagonista e que en conciencia estou moralmente obrigado a historiar, aporto o meu gran de area para que os fillos da cidade episcopal (...) farán do dominio público revelando a gravidade do alí acontecido. (1996: 317)

\section{E Enrique Vigo:}

Non procuro con elas [refirese ás memorias] nada que non sexa achegar o meu grao de area para que se defenda a liberdade con unllas e dentes e para que os partidarios do franquismo non oculten a verdade histórica. Se a lectura deste libro axuda entender isto a unha soa persoa, pagará a pena. (2004: 63-64)

Incluso nos autores que imprimen ás súas obras unha maior forma literaria, latexa a mesma intencionalidade ${ }^{21}$ (claro que, nestes casos, as súas xustificacións non forman parte do texto na novela, senón do tecido paratextual):

o autor non pretende atizar con el a fogueira do resentimento, que xa demasiada leña se ten queimado no forno recalcitrante da discordia. O que si se propón é tributar unha homenaxe de merecida relembranza ós seus zarandeados protagonistas, ó mesmo que proxectar un relampo de luz na conciencia de todos aqueles que fixeron da contenda fratricida unha orxía macabra. (Fernández Pérez 1996: 7)

E se a filiación política arriba mostrada foi o seu "delito" e as causas que os levaron á escrita a súa "redención", estas foron as posibilidades con que contaban para sobrevivir: 1) alistarse na fronte loitando a favor dos seus (Scórpio; na parte final e de maneira presentida, don Ozores, e o protagonista da segunda parte); 2) fuxir, que tamén podía derivar en alistarse na fronte, pero no bando nacional, e dende aí planear unha fuxida (don Ozores e Elixio Rodríguez).

A vía máis xeneralizada foi a fuxida, e segundo Grandío (2005: 1000-2) estas eran as posibilidades que se barallaban:

Agacharse nos seus domicilios ou noutros espazos, desprazándose de casa en casa ata conseguir unha saída segura [don Ozores, Juan Noya e Alonso Ríos].

Esconderse no monte [don Ozores].

Integrase na Falanxe ou no exército [o Mauro de Del Riego, don Ozores, Elixio Rodríguez] (coa intención de pasarse ao outro lado), nalgúns casos converténdose en perseguidores ou delatores.

Fuxir por vía terrestre cara a Asturias-Lugo ou Portugal, ou por vía marítima a Portugal ou Francia [Carlos Aranda e Alono Ríos -por vía terrestre a Portugal-; Elixio Rodríguez e Juan García-vía Francia e tamén por terra].

Non obstante, pensamos correcto engadir outra alternativa (que no mellor dos casos podía ser un paso previo a unha fuxida): o cárcere. Por el pasaron Esmoriz, Carlos Aranda, os personaxes da segunda novela de Valenzuela, García Durán, Juan Noya, Xerardo Díaz, Evaristo A. Mosquera e Enrique Vigo.

${ }^{19}$ É interesante tamén o nome que o xornalista dá ao libro: "biografía política".

${ }^{20} \mathrm{Na}$ "Introdución" (1985: 13-14) dinos que lle interesa dar a coñecer un dos episodios máis amargos da nosa historia recente e facelo dende a estrita veracidade. Confirma que os nomes dos personaxes referidos son reais, agás un, Agustín, que é un pouco a conxunción de todos. E confesa non lembrar todos os feitos.

${ }^{21}$ Aínda que Camiño Noia aplique esta característica a catro libros, o dito pode extrapolarse á gran maioría: "Foron escritas para conta-la experiencia dos seus autores na guerra e no exilio. Son unha especie de memorias da represión..." (2000: 91). 


\subsection{OS ESPAZOS}

Posto que vimos de enumerar as vías de escape con que contaban os nosos narradores, e xa que sabemos que as súas narracións son a historia da súa supervivencia, vexamos, novamente de maneira moi xeral, cales son os espazos referidos en cada unha destas obras. E xa que o cárcere ocupa un papel central, unha primeira clasificación será aquela que estableza dous grandes grupos: obras que transcorren en espazos abertos e obras de espazos pechados.

Podemos chamar "obras pechadas" as que non coñecen máis ca un espazo, o cárcere: Esmoriz, Os que non morreron, A crueldade inútil e Catro anos a bordo dunha illa. Como é lóxico poden referir os acontecementos precedentes ao encarceramento (a noticia da sublevación en Marrocos, o despregamento das tropas franquistas na Península e a súa detención), pero non os que veñen despois. Un caso atípico é Esmoriz, que se detén máis na descrición das intimidades do eu que na experiencia carceraria.

Neste grupo de narracións é interesante profundar na descrición das dependencias de prisión, así como na evolución da guerra ou nas noticias que sobre esta lles chegaban. E todo isto visto por quen aínda descoñecía a súa condena ${ }^{22}$ e tiña, evidentemente, outras preocupacións (temores recorrentes eran a celebración dos seus xuízos e a súa sentenza, ou a "saca" a medianoite para lles inferir o tiro de graza, que logo inscribirían como "pulmonía traumática" en causa da morte ${ }^{23}$ ).

Tematicamente (deixando de lado os temores referidos) podemos sinalar como recorrentes as conversas sobre a marcha da guerra (e a esperanza depositada na vitoria aliada), o papel da igrexa no conflito, as condicións das celas ou o trato dos que os controlaban. Véxanse algúns fragmentos de $O$ s que non morreron:
Discutíamos sobor a marcha da guerra. Era o noso cabalo de batalla. Sempre chegabamos á mesma conclusión: o sentimento de desfeita e de frustración. Nembargantes, había intres en que a paixón nos facía ver as cousas de outro xeito máis riseiro e nonos dabamos por vencidos... (Díaz Fernández 1985: 19)

Naquelas circunstancias unha acusación dese xeito era unha sentencia de morte. Parecíame inacreditábel que un crego poidera facer con tan repentenexo tal inculpación; el sabía que o estaba condeando; el sabía que con calar, salváva-lle a vida; pero o Deus do perdón non era pra os nemigos; a Igrexia do Cristo traicionado estába-o condenando. (ibid. 80)

-Non, meu filliño, a ti non che poden matar! Ti non fixeches mal a ninguén...

— $\mathrm{Si}$, nai, si! Van-me fusilare! (...) (...)

—Ai Deus,! Por que? Non pode ser, non!

- Non teñas mágoa, naiciña, que eu xa non teño medo. Ao millor indúltanme por ser moi xoven -o rapaz tiña 20 anos-; e si non... algunha vez tiña que morrer... (ibid. 81)

Ao que un compañeiro de prisión replica:

-Esto xa pasa de marca; non hai razón para tanta ruindade. Desespéro-me por tanta vileza e sufro pola miña imposibilidade! Como anceio que houbera un Deus pra berrar-lle, pra blasfemar-lle, pra chamar-lle de todo! Diría-lle da súa maldade... de todo o que teño eiquí que me envenena... (ibid. 82)

Ou sobre o trato dos carcereiros o que di Elixio Rodríguez:

Os devanditos carcereiros competían entre si a maltratar ás víctimas; asañándose aínda máis cos que eramos coñecidos seus ou veciños (...) un dos carcereiros, sen chegar a maltratarme fisicamente, non deixaba de humillarme por tódolos medios ó seu alcance -a pesar da excelente amizade que a miña familia mantiña coa súa muller. Foi para min unha amarga sorpresa

${ }^{22}$ Neste sentido é interesante pór en relación as dúas memorias de Xerardo Díaz. A primeira con esa anguria continua do non saber e a segunda coa indiferenza da espera: "As nosas vidas xa non tiñan esa sensación acongoxada da espera, tiñan máis ben a apatía da renunciación, pois morríamos pouco a pouco aplastados pola certeza da derrota...” (1985: 63).

${ }^{23}$ Téñase en conta que Xerardo Díaz estivo no mesmo cárcere do que sacaron e asasinarona Díaz Baliño, Ánxel Casal, Pepiño Areosa, os irmáns Sixto e tantos anónimos. 
comprobar como este individuo, ata daquela aparentemente bo veciño e amigo, fora convertido, máis que en adversario meu, en inimigo implacable e sádico... ${ }^{24}$ (Rodríguez 1994: 54)

De Elixio, por ter coñecido o cárcere franquista e o republicano, é interesante a contraposición que fai dos dous "mundos", aínda que o maniqueísmo estea sobre todo patente nas novelas de Valenzuela:

O meu compañeiro gabou o ambiente da prisión onde, segundo el, os presos eran tratados como seres humanos, con todo respecto. Despois do seu discurso sobre o espléndido sistema penitenciario, aclaroume que ese bo trato ós presos podería obedecer a que alí dentro se atopaban detidos o mellor dos inimigos da República: bispos, banqueiros, nobres, xenerais, terratenentes... que eran visitados con frecuencia por xornalistas estranxeiros, ós que se quería impresionar de maneira favorable. (Valenzuela 1994: 174)

Retomando a clasificación anterior, todas as demais obras son de espacialidade aberta, pois son varios os escenarios que aparecen, o que nos leva a facer unha segunda clasificación, segundo cales sexan os lugares nomeados. Neste sentido, podemos opoñer narracións de grandes urbes a pequenas.

Scórpio e Memorias dun antifranquista son as que mellor encaixan no primeiro bloque. Transcorren en escenarios claramente urbanos: Ferrol, Santiago de Compostela, Madrid... Tamén as dúas de Fernández Pérez e $O$ silencio redimido, pero neste caso, fóra de solo español. Portugal é o núcleo das respectivas andanzas dun e outros (Carlos Aranda por unha banda e Ramón Cudeiro e Senén Bentraces da outra).

A aparición de Portugal vainos servir para facer unha nova confrontación: narracións en solo español vs. narracións en terras portuguesas (enténdase como escenario principal, pero non único; de feito, as tres novelas mencionadas non transcorren, soamente, en Portugal, senón tamén en América).

Mais volvamos á primeira distinción: urbano vs. non urbano ou rural. Matádeo mañá, $A$ loita antifranquista, Non agardei por ninguén e Era tempo de apandar tamén transcorren en grandes urbes, pero nestes casos quizais sexa mellor falar de "pluri-espazos". As catro narracións transcorren en escenarios moi variados, polo que é difícil destacar un sobre os outros. Pero, polo xeral, os espazos amplos son máis importantes ca os pequenos, as cidades ou vilas sobre as aldeas ${ }^{25}$. Por exemplo: Elixio Rodríguez está en Sevilla, León, Valencia, Francia...; García Durán na Coruña, Madrid...; Ramón de Valenzuela en Cáceres, nas inmediacións de Madrid, en Francia... (pero tamén nas terras do Deza).

Aquí sería conveniente facer outra matización pois, como vimos, aparecen espazos internacionais: Francia, por exemplo. Xa que logo, non só confrontamos España con Portugal, senón con Europa, e incluso con América (México, no caso de Elixio Rodríguez e a Arxentina en Juan Noya). Porén, a intromisión dos países americanos ten unha explicación moi clara: son países de "acollida" posterior ao 39. Por outra banda, Portugal e Francia adoitan ser lugares de paso, países ponte para, normalmente, chegar a América. Aínda que tamén lugares de agocho (mentres agardan o final da guerra e, polo tanto, o regreso a Galicia -Fernández Pérez en Don $\mathrm{Ga}$ bino- ou como vía de escape cara a América).

Por outra banda, estarían as narracións en ámbitos máis pequenos, polo xeral en áreas rurais. É o caso de $O$ Siñor Afranio (que aínda que tamén transcorre en Portugal, non o fai en grandes cidades como Lisboa, caso de Terra coutada), Juan Noya e Fernández del Riego.

\footnotetext{
${ }^{24}$ Moitas son as referencias, nestes libros, á "conversión” de veciños e compañeiros.

${ }^{25}$ Téñase en conta que nas obras que transcorren en solo urbano, polo xeral son varios os espazos que aparecen, resultado de ser obras máis "dinámicas" (cárcere, fuxida, busca dunha nova vida...). Polo que quizais fose mellor falar de "medios urbanos". Polo xeral, nas obras de escenario máis reducido (ámbito rural) os desprazamentos son menores.
} 


\subsection{O TEMPO}

Respecto ao tempo -cronoloxía- habería que facer unha dupla clasificación, segundo consideremos máis importante o trienio 19361939 ou tamén algún ano posterior. Só estaría no segundo grupo Era tempo de apandar e, con reticencias, O cego de Pumardedón. A primeira novela transcorre cando xa rematou a guerra. A de Fernández del Riego tamén é de posguerra, non obstante, o cerne da narración son os recordos sobre a fronte, a batalla en si, co que podemos considerala un produto híbrido, segundo falemos da época da narración ou da época do narrado.

Todas as demais toman como punto de referencia o 36 e o levantamento das tropas de Franco. Incluso A crueldade inútil comeza cando aínda non rematou a guerra, aínda que se estenda máis alá; como tamén o fan Matádeo mañá, A loita antifranquista ou Fuxidos. Unha excepción ao exposto, pero non por isto factible de se encadrar no grupo precedente, é Scórpio que, como dixemos, é prebélica; polo tanto, o caso contrario a Era tempo de apandar.

\section{CONCLUSIÓN}

Se ben é certo que o tema da Guerra Civil foi tardiamente tratado $^{26}$ (poida que algún dos condicionante fosen o medo, a desgana...), cremos que si o foi abundantemente. $\mathrm{E}$ isto demóstrannolo non só as 16 narracións obxecto de estudo, senón tamén o amplo número de novelas que recrean dalgún xeito esta época e enchen hoxe en día os andeis das nosas librerías (Agosto do 36, Os libros arden mal, As rulas de Bakunin, Cardume...). Parece claro, pois, o interese que a narrativa "memoríaslistica" ${ }^{27}$ suscita, e non só como fonte de entretemento, senón tamén como forma de coñecemento e de contribución á recuperación dunha historia, non só falseada, senón tamén descoñecida. Mais que estas formas literarias veñan da man de autores que viviron persoalmente a contenda e o tempo posterior confírelles, ao noso entender, un carácter singular, non só polas razóns que levaron a escribilas, máis tamén por ese valor documental que encerran. Non parece acertado supoñer que estes autores pretendesen, ao escribilas, (re)abrir vellas feridas, nin é xusto que a nós, ao lelas (ou estudalas), se nos acuñe de "nostálxicos"... Como outro supervivente dunha guerra similar, Primo Levi, deixou escrito: "se comprendere è impossibile, conoscere è necesario" (1976: 175). Daquela, deixemos de pactar coa desmemoria e tentemos coñecer, aínda que sexa baixo o veo da ficción, esa época.

\section{REFERENCIAS BIBLIOGRÁFICAS}

Alonso Montero, Xesús e Miro Villar (coords.) (1999): Guerra Civil (1936-1939) e literatura galega (textos e documentos para unhas xornadas de estudio e debate). Santiago de Compostela: Consello da Cultura Galega.

Alonso Ríos, Antón (1979): O Siñor Afranio Ou como me rispéi das gadoupas da morte. Vigo: Castrelos [O Siñor Afranio Ou como me rispei das gadoupas da morte. Memorias dun fuxido. Vigo: A Nosa Terra, 2006].

BernárdeZ, Carlos et al. (2001): Literatura galega. Século XX. Vigo: A Nosa Terra.

Bertrand de Muñoz, Maryse (1982): La Guerra Civil española en la novela. Bibliografía comentada. Madrid: José Porrúa Turanzas, 2 vols.

Carballa, Xan (2006): Entrevista a Enrique Mosquera Durán (fillo de E. Antonio Mosquera), en A Nosa Terra. Periódico Galego Semanal 1230, p. 17.

\footnotetext{
${ }^{26}$ Véxase Alonso Montero e Miro Villar (2006: 169-70) e Vilavedra (1999: 209).

${ }^{27}$ Este é o nome que dan a este tipo de literatura Bernández et al. (2001: 153).
} 
Carballido Reboredo, Silvia (2001): Novela en pé de guerra. A Guerra Civil vista polos novelistas galegos en castelán. Sada: Ediciós do Castro.

Carballo Calero, Ricardo (1989): Scórpio. Santiago de Compostela: Sotelo Blanco.

DíAz Fernández, Xerardo (1985): Os que non morreron. Sada: Ediciós do Castro. (1985): A crueldade inútil. Sada: Ediciós do Castro.

Dobarro Paz, Xosé María (2007): "Xerardo Díaz en Montevideo", en Actas doCongreso Internacional "O exilio galego"e repertorio bibliográfico. Santiago de Compostela: Consello da Cultura Galega, Arquivo da emigración, pp. 686-707.

FernándeZ del Riego, Francisco (1992): O cego de Pumardedón. Vigo: Ir Indo.

FERnÁNDEZ PÉREZ, Antonio (1990): Terra coutada. Vigo: Galaxia. (1996): Don Gabino. Vigo: Galaxia.

FERnÁNDEZ Prieto, Lourenzo (1996): "Guerra civil e franquismo”, en X. M. Vázquez Varela et al., Nova historia de Galicia. A Coruña: Editorial Tambre, pp. 451-510.

FERnÁNDEZ SANTANDER, Carlos (1986): Bibliografia de la novela sobre la guerra civil española. A Coruña: Librería Arenas.

FERnÁNDEZ, E. (2006): “Medra a bibliografia do 36 en Galicia”, Revista Biblos. Clube de lectores 21, p. 6.

García Durán, Juan (2001): Pola liberdade. A loita antifranquista de Luís Costa. Vigo: A Nosa Terra.

GonzÁlez Gómez, Xesús (1992): “As memórias dunha xeración eivada. O cego de Pumardedón de Paco del Riego", A Nosa Terra. Periódico galego semanal 524, p. 19.

Grandío Seonne, Emilio (2005): Actas do congreso de Narón. A represión franquista en Galicia (2003). Narón: Asociación Cultural Memoria Histórica Democrática.

Hermida GarcíA, Modesto (1989): “Introdución” a Ramón Valenzuela, Non agardei por ninguén. Vigo: Xerais, pp. 11-40.

LeVI, Primo (1976): Se questo è un uomo. Torino: Einaudi.

Mosquera, Evaristo A. (2006): Catro anos a bordo dunha illa. Memoria dun preso en San Simón ou un estraño xeito de vivir a nosa guerra civil. Vigo: A Nosa Terra.

Noia CAmpos, Camiño (2000): "A narrativa de posguerra", en A. Tarrío (coord.),Galicia. Literatura. Tomo XXXIV: A literatura desde 1936 ata hoxe: narrativa e traducción. A Coruña: Hércules, pp. 88-148.

Noya Domínguez, Juan (1996): Fuxidos. Vigo: Xerais.

Otero, Aníbal (1994): Esmoriz. Santiago de Compostela: Sotelo Blanco.

Quiroga Díaz, J. Carlos (1987): "Scórpio: História rosa e narrador polifónico", Agália. Revista de Estudos na Cultura 12, pp. 486-488.

RodríGuez, Elixio (1994): Matádeo mañá. Vigo: Xerais.

Rodríguez Fer, Claudio (2001): "Introdución" a Carballido Reboredo. Novela en pé de guerra. A Guerra Civil vista polos novelistas galegos en castelán. Sada: Ediciós do Castro.

(2006): "Literatura galega na Guerra Civil. Estados da cuestión", en X. Alonso Montero e M. Villar (coords.), Guerra Civil e Literatura Galega (1936-1939). Vigo: Xerais, pp. 169-176. 
RodríGuez SANTAMaría, Xoán PASTOR e Román ArÉn (2006): Un río de sangue e tinta. A Guerra Civil española e o franquismo na narrativa dos galegos. Boiro: "A. C. Barbantia" / Concello de Boiro.

Rodríguez SuÁrez, María (2006): Narrativa autobiográfica da Guerra Civil. Traballo de Investigación Titorizado. Santiago de Compostela: Universidade.

SACO, Fernando (2006): Os irmáns Saco. Ou a loita galeguista baixo o franquismo. Vigo: A Nosa Terra.

Santiago, Silvio (1989): O silencio redimido. Historia dun home que pode ser outro. Vigo: Galaxia.

VAlenZuela, Ramón (1980): Era tempo de apandar. Madrid: Akal.

(1989): Non agardei por ninguén. Vigo: Xerais.

VilaVEDRA, Dolores (2006): "Nova xeira para un tema vello", Revista Biblos. Clube de lectores 21, p. 4 (dipoñible en: http://www.biblosclube.com/pdf/revista21.pdf).

VIGO, Enrique (2004): Memorias dun antifranquista. Ferrol: Ed. Embora. 